proposes three possible models to neutralize the moral deterioration of power and realize its political actualization among the population.

Keywords: power, opposition, political regime, moral deterioration, political conflict, destabilization, color revolutions, elite

УСМАНОВА Заира Романовна - кандидат политических наук, доцент департамента политологии факультета социальных наук и массовых коммуникаций Финансового университета при Правительстве РФ (125993, Россия, г. Москва, ГСП-3, Ленинградский пр-кт, 49; ZRUsmanova@fa.ru) ШАШЕНКОВ Александр Олегович - аспирант департамента политологии факультета социальных наук и массовых коммуникаций Финансового университета при Правительстве РФ (1255993, Россия, г. Москва, Ленинградский пр-кт, 49; AOShashenkov2019@edu.fa.ru)

ВОРОПАНОВ Сергей Александрович - аспирант департамента политологии факультета социальных наук и массовых коммуникаций Финансового университета при Правительстве РФ (1255993, Россия, г. Москва, Ленинградский пр-кт, 49; SAVoropanov2019@edu.fa.ru)

\title{
РИСКИ РЕФОРМИРОВАНИЯ ГОСУДАРСТВЕННОЙ СОЦИАЛЬНОЙ И ЭКОНОМИЧЕСКОЙ ПОЛИТИКИ В СОВРЕМЕННОЙ РОССИИ
}

\begin{abstract}
Аннотация. В статье представлены результаты исследования, проведенного группой молодых ученых в рамках проекта «Социально-экономическое неравенство в России: тенденции и адаптация успешных зарубежных практик по преодолению/смягчению бедности». Часть исследования посвящена проблемам реформирования государственной социальной и экономической политики в России, а также возможностям преодоления негативных практик. Предложенные в статье группы факторов риска выявлены и заложены в компаративную матрицу, позволяющую качественно оценить взаимосвязь и взаимозависимость социальных, экономических, политических, правовых, демографических, экологических, информационных трансформаций. Составленная авторами схема характеризуется аналитическим синергизмом и эмерджентностью. В качестве выводов установлено, что большинство рисков находятся в состоянии взаимовлияния и взаимозависимости. В связи с этим социально-экономические меры должны быть гармонизированы и сращены практически со всеми направлениями деятельности государства.
\end{abstract}

Ключевые слова: бедность, социальная эксклюзия, социальная политика, экономическая политика, политические реформы, риски.

Актуальность исследования. В Указе Президента РФ «О национальных целях и стратегических задачах развития Российской Федерации на период до 2024 года» в качестве одной из национальных целей обозначено двукратное снижение бедности ${ }^{1}$. Проблема бедности и значительного разрыва в доходах беднейших и богатейших слоев общества актуальна практически во всех странах мира. Большинство из них во главу национальной политики ставят цели экономического развития и построения социального государства. Существуют как умеренные, так и радикальные прогнозы, по которым природные, техногенные, гуманитарные катастрофы и эпидемии, а также последующие за ними эконо-

1 Указ Президента РФ от 07.05.2018 № 204 «О национальных целях и стратегических задачах развития Российской Федерации на период до 2024 года». Доступ: http://kremlin. ru/acts/bank/43027 (проверено 12.06.2020). 
мические и политические кризисы в дальнейшем усугубят проблему бедности и социально-экономического расслоения в мире. Для России, которая весь период своего постсоветского существования борется с бедностью, эта проблема в настоящее время в очередной раз стала острой, особенно в контексте необходимости оценки возможных рисков социально-экономического реформирования. Последнее десятилетие для нашей страны характеризуется противоречивыми реформами, ухудшением макроэкономических и геополитических условий, которые препятствуют усилиям государства в борьбе с бедностью и расслоением общества.

Методология исследования. Целью исследования является выявление и группировка основных рисков, которые могут повлиять на эффективность реализации социально-экономических реформ в России в настоящее время. В рамках нашего исследования под риском мы понимаем вероятность нарушения нормального развития, а также препятствия для реализации целей, задач и гарантий социальной, экономической, информационной, экологической, инновационной политики, в т.ч. кризис правового государства, высокий уровень коррупции на всех уровнях власти, дезорганизацию административной системы. На наш взгляд, указанные тенденции в силу действия закона эмерджентности систем могут влиять друг на друга и усиливать непредсказуемость характера развития событий. Также мы исходим из того, что взаимовлияние сразу нескольких кризисных явлений в различных сферах (не всегда одного порядка) с большой долей вероятности может привести к политическим рискам - системному кризису власти, дестабилизации общественных отношений, всплеску преступности, углублению социального расслоения, протестным акциям.

В данной статье представлен метод матричной компаративной группировки возможных рисков проведения реформ, представленный авторской матрицей рисков реформирования государственной социальной и экономической политики в области снижения бедности и преодоления социально-экономического неравенства в Российской Федерации. Группируя факторы риска, обоснованные российскими учеными в различных исследованиях, мы исходим из предположения, что одни и те же риски могут синергично влиять на разные процессы: последовательные, параллельные, дискретные, взаимосвязанные. При этом предложенную матрицу характеризуют синергизм и эмерджентность, что позволяет сделать вывод о необходимости разработки превентивных мер в отношении всех групп рисков, а также готовности к «кризисному государственному управлению» при их наступлении.

С целью операционализации понятийного аппарата исследования необходимо уточнить, что под социальной политикой в данной статье мы понимаем разработку и реализацию государством комплекса мер по поддержке социально незащищенных групп населения и предотвращение попадания в их ряды граждан, составляющих группу риска бедности и неблагополучия (например, членов многодетных семей и т.п.). Реализуя меры социальной политики, государство остается гарантом (хотя не исключено участие в подобной деятельности общественных структур и благотворителей) в области создания условий для всестороннего развития личности, равного доступа к благам, гармоничных взаимоотношений социальных классов и минимизации конфликтов, обеспечения социальной справедливости, особенно для групп, составляющих риск бедности и неравенства ${ }^{1}$. Под экономической политикой мы понимаем деятельность

1 Указ Президента РФ от 07.05.2012 N 597 «О мероприятиях по реализации государственной социальной политики». Доступ: http://www.consultant.ru/document/cons_doc_ LAW_129344/ (проверено 12.06.2020). 
государства, связанную с разработкой и реализацией комплекса мер по поддержке хозяйствующих субъектов всех форм собственности, а именно создание правовых, бюрократических и иных регуляторных условий для укрепления и роста национальной экономики ${ }^{1}$. При этом любая реформа как поступательное движение к изменению параметров системы, трансформации регуляторных условий, правил взаимодействия субъектов может привести как к изменению системы, так и к ее разрушению. Именно поэтому обращение к проблеме риска имеет большое значение для политического прогнозирования и сценарирования с целью проработки и оценки возможностей предупреждения негативных тенденций либо борьбы с их последствиями.

Результаты исследования. В этой части статьи мы кратко опишем некоторые группы рисков и факторы, обусловливающие их. Первая группа - социальные риски, которые, по утверждению В.А. Лапшова, связаны с ситуацией неопределенности в обществе и слабой эффективностью государственной социальной политики [Лапшов 2018]. К факторам, которые могут составлять риск слабой или неэффективной реализации социальных мер, можно отнести: проблемы развития ЖКХ; проблемы развития системы образования [Лоскутова, Синяев 2019]; проблемы системы здравоохранения (и с некоторыми из них российское государство столкнулось уже сейчас, в условиях пандемии ${ }^{2}$ ); сложности с повышением качества жизни [Соболь 2018]; трудности с обеспечением населения жильем [Ярных, Агентова, Барш 2019]; отсутствие базы для повышения заработных плат ${ }^{3}$; невозможность решения проблемы бедности пенсионеров 4 ; затруднения с модернизацией социальной сферы [Корф 2017]; экологические риски в контексте социальной политики [Порфирьев 2019; Кожевников, Лебедева 2019]; систематический рост негативных ожиданий и упадок социальных настроений в российском обществе.

На наш взгляд, высокие оценочные риски и негативные ожидания российского общества связаны со спецификой современной политико-культурной трансформации в нашей стране. Наблюдая в настоящее время достаточно взвешенное нормотворчество в области социальных программ, мы сталкивается с системным кризисом административно-управленческого аппарата, высоким уровнем коррупции. На наш взгляд, научные выводы, полученные доктором экономических наук Т.В. Чубаровой и кандидатом экономических наук Е.Е. Шестаковой (Институт экономики РАН), имеют большое значение для понимания проблемы рисков социальной политики в России. Ученые особо выделяют функции государства, которые необходимо реализовать, чтобы минимизировать структурные социальные риски [Чубарова, Шестакова 2018]. Мы бы добавили некоторые значимые идеи: так, распад семьи разрушает традиционные домохозяйства, и женщины с детьми, даже при условии их занятости, пополняют ряды бедных; офисные работники, ввиду автоматизации и цифровизации процессов, получают невысокие зарплаты, и сам рынок труда

${ }^{1}$ Единый план по достижению национальных целей развития РФ до 2024 г. Доступ: http:// static.government.ru/media/files/j8IV1FkssLpUqI89JCXZ2mLiIiLEn7H8.pdf (проверено 12.06.2020).

2 Какие проблемы в системе здравоохранения РФ выявила пандемия. Доступ: https:// rg.ru/2020/06/03/kakie-problemy-v-sisteme-zdravoohraneniia-rf-vyiavila-pandemiia.html (проверено 12.07.2020).

3 «Созидательное разрушение» России. Повышение зарплат граждан стало тормозом экономического роста. Доступ: http://www.ng.ru/economics/2020-01-20/1_7772_salary.html (проверено 12.06.2020).

4 Миллионы пенсионеров - потенциальные бедняки. Численность россиян, которым надо доплачивать до прожиточного минимума, стремительно растет. Доступ: http://www. ng.ru/economics/2019-08-15/1_7651_poorness.html (проверено 12.06.2020). 
менеджеров низшего звена переполнен; встает вопрос о переквалификации персонала и «смерти» многих профессий в ближайшем будущем; автоматизация производства и сельского хозяйства ставит вопрос о «вымирании» целого спектра рабочих специальностей; урбанизация влечет риски криминализации сельских местностей и т.д. В таком случае необходимо понимать социальную политику как риск-менеджмент, или предупреждение социальных рисков, что предполагает работу не только с категориями бедных, но и с категориями риска бедности.

Вторая, особая группа - информационные риски. В классической экономике они не рассматривались как существенные, но в условиях постиндустриального общества «виртуальные» риски стали основополагающими. С помощью технологий манипулирования информацией, особенно посредством цифровых средств коммуникации, можно управлять целой индустрией (от развязывания соляного кризиса ${ }^{1}$ до торговых войн). Современные коммуникативные технологии напрямую влияют на характер взаимодействия общества и власти, они могут как способствовать стабилизации общественно-политических отношений, так и стимулировать высокие риски (эффект «распыленной власти»). Среди рисков информационного общества М.А. Лимонова и М.В. Синяев выделяют: подмену информированием реальной деятельности властей; выделение социальных благ государством в ответ на угрозу дестабилизации, а не в рамках системной работы; зависимость в принятии властных решений от «кричащего меньшинства» [Лимонова, Синяев 2019]. Информационные риски связаны с высоким уровнем конфликтности общества так же, как и с высокой возможностью достижения согласия, и победа одной или другой парадигмы всецело зависит от государственного управления информационными потоками, т.е. государственной информационной политики. Мы имеем в виду борьбу государства с fake news - незаконным контентом, информацией, разжигающей конфликты, заведомо ложной и вводящей в заблуждение, а также формирование потоков объективной информации по всем темам, интересующим общество.

Что касается политических, финансово-экономических, экологических и правовых факторов риска, то они будут подробно описаны в серии последующих статей по результатам исследования.

Bыводы. Проанализировав комплекс проблем, которые составляют риски реформирования социальной и экономической политики в России, можно заключить, что государству необходимо заниматься предупреждением рисков. Мерой превенции служит социальная ответственность власти и бизнеса, т.е. установление пределов перераспределения благ и учет интересов всех слоев общества на основе принципов солидарности. Также матричный анализ наглядно показывает, как все риски связаны между собой. Наступление одних рисковых условий может повлечь усиление вероятности наступления других рисков. Поэтому государству надо смотреть на проблему рисков комплексно, а бюрократической прослойке управленцев быть готовыми к кризисному управлению. Также матричный анализ показал, что одни и те же риски усиливаются с точки зрения вероятности и величины последствий в зависимости от мягкости и жесткости реформ. При этом неопределенность прогнозирования, о которой пишут многие ученые - экономисты, социологи, политологи, свидетельствует о том, что нельзя с высокой точностью ожидать более или менее значительного эффекта от внедрения конкретных мер государственной политики по борьбе с

1 Соляной кризис 2006 г. Доступ: https://www.kommersant.ru/doc/850665 (проверено 12.06.2020). 
Таблица 1

Матрица рисков реформирования государственной социальной и экономической политики в области снижения бедности и преодоления социально-экономического неравенства в Российской Федерации ${ }^{1}$

\begin{tabular}{|c|c|c|}
\hline \multicolumn{2}{|c|}{ Жесткость реформ / Мягкость реформ (популизм) } & \multirow{2}{*}{ 兽 } \\
\hline $\begin{array}{c}\text { Социальная сфера: содержание фактора } \\
\text { риска }\end{array}$ & $\begin{array}{c}\text { Экономическая сфера: содержание } \\
\text { фактора риска }\end{array}$ & \\
\hline $\begin{array}{l}\text { Углубление экономического } \\
\text { неравенства, воспроизводство бедности } \\
\text { («ловушка бедности») } \\
\text { Риск бедности для групп, находящихся } \\
\text { на границе бедности } \\
\text { Потеря статуса социальной } \\
\text { незащищенности } \\
\text { Распад семьи (увеличение бедности) } \\
\text { Социально-демографические риски } \\
\text { (старение, убыль населения) } \\
\text { Исключение из рынка труда (потеря } \\
\text { трудоспособности, квалификации) } \\
\text { Безработица } \\
\text { Низкая квалификация, присущая } \\
\text { бедным слоям общества } \\
\text { Автоматизация и цифровизация } \\
\text { производства и «смерть профессий» } \\
\text { Неконкурентность образования } \\
\text { Урбанизация, слабая инфраструктрная } \\
\text { обеспеченность провинции } \\
\text { Рост бюрократических кадров } \\
\text { Трансформация рынка труда }\end{array}$ & $\begin{array}{l}\text { Дефицит бюджетов на социальную } \\
\text { сферу } \\
\text { Социальное отчуждение населения от } \\
\text { бизнеса и власти } \\
\text { Упадок деятельности профсоюзов } \\
\text { Нездоровая конкуренция на рынке } \\
\text { труда } \\
\text { Низкий уровень оплаты труда } \\
\text { Выплата зарплат по «серым» и } \\
\text { «черным» схемам } \\
\text { Ущемление трудовых прав работников } \\
\text { (отсутствие выплат за работника в } \\
\text { ФСС, ПФР и др.) } \\
\text { Автоматизация производства и } \\
\text { сокращение штатов, выплата выходного } \\
\text { пособия } \\
\text { Увеличение затрат на социальную сферу } \\
\text { Неблагоприятная демографическая } \\
\text { ситуация («демографический крест») } \\
\text { Недостаток квалифицированной } \\
\text { рабсилы/переизбыток } \\
\text { неквалифицированной } \\
\text { «Утечка мозгов» } \\
\text { Безработица } \\
\text { Изменение конъюнктуры рынка труда } \\
\text { Разрывы в развитии регионов, трудовая } \\
\text { миграция, урбанизация }\end{array}$ & 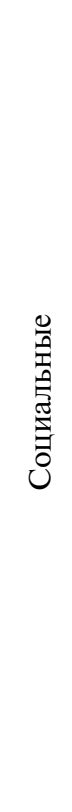 \\
\hline $\begin{array}{l}\text { Рассогласование интересов слоев } \\
\text { общества } \\
\text { Манипуляция информацией с целью } \\
\text { дестабилизации режима } \\
\text { Фейковые новости } \\
\text { Негативная или оппозиционная } \\
\text { пропаганда } \\
\text { «Черный РR» / «джинса» } \\
\text { Распространение информации } \\
\text { экстремистского и иного незаконного } \\
\text { характера }\end{array}$ & $\begin{array}{l}\text { Рассогласование интересов слоев } \\
\text { общества } \\
\text { Информационное противостояние } \\
\text { бизнеса, власти и общества } \\
\text { Утечка персональных данных } \\
\text { Промышленный шпионаж } \\
\text { Кража технологий } \\
\text { Обнародование внутрикорпоративной } \\
\text { информации, охраняемой от } \\
\text { конкурентов } \\
\text { Информационные войны }\end{array}$ & 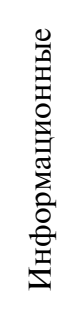 \\
\hline
\end{tabular}

1 Матрица разработана авторами. Ее особенностью является нахождение схожих факторов риска в разных группах (сферах), что свидетельствует о взаимосвязи общественных отношений и процессов и невозможности их рассмотрения в отрыве друг от друга. Представленные в ней факторы риска не являются исчерпывающими, т.к. были обнаружены и выделены с помощью анализа научной литературы и предполагают последующее дополнение. Мы исходим из того, что масса факторов имеют непредсказуемый и слабо прогнозируемый характер, а также степень их влияния на общественные отношения зависит от специфики политических решений о жесткости или мягкости проводимых в стране реформ. Тем не менее качественная экспертная оценка факторов риска, формулирование на их основе пула рекомендаций для органов государственной власти может снизить негативный рисковый потенциал на практике. 
бедностью, но, однозначно, следует быть готовыми ко всем сценариям сразу. То есть, «Пластичность» государственного менеджмента, теоретически готового к различным прогнозным сценариям, вероятно, даст более высокий результат с точки зрения эффективности реализации мер по борьбе с бедностью и снижению социального расслоения.

Статья подготовлена по результатам исследований, выполненных за счет средств Научного фонда по заданию Финуниверситета.

\section{Список литературы}

Кожевников С.А., Лебедева М.А. 2019. Проблемы перехода к зеленой экономике в регионе (на материалах Европейского Севера России). - Проблемы развития территории. № 4(102). С. 72-87.

Корф В.И. 2017. Управление рисками в сфере социальной защиты населения. - ВЭПС. № 1. С. 146-149.

Лапшов В.А. 2018. Риски социальной политики в современном российском обществе. - Вестник Московского государственного лингвистического университета. Общественные науки. № 3 (806). С. 178-189.

Лимонова М.А., Синяев М.В. 2019. Риски становления социального государства в РФ в условиях современных технологий организации взаимодействия власти и населения. - Общество: социология, психология, педагогика. № 7. C. $35-43$.

Лоскутова И.М., Синяев М.В. 2019. Соотношение традиционных и новых социально-политических рисков в процессе становления социального государства и реформирования системы образования в РФ. - Теория и практика общественного развития. № 1(131). С. 13-17.

Порфирьев Б.Н. 2019. Парадигма низкоуглеродного развития и стратегия снижения рисков климатических изменений для экономики. - Проблемы прогнозирования. № 2(173). С. 3-13.

Соболь Т.С. 2018. Современный уровень и качество жизни населения России. - Вестник Московского университета им. С.Ю. Витте. Сер.1. Экономика и управление. № 2(25). С. 7-14.

Чубарова Т.В., Шестакова Е.Е. 2018. Структурные социальные риски как последствия социальной политики современного государства: методологические аспекты. - ВТЭ. № 1(2). С. 89-100.

Ярных Э.А., Агентова Г.В., Барш Т.И. 2019. Статистическое изучение обеспеченности россиян жильем. - Россия: тенденции и перспективы развития. № 4-1. C. 928-932. 
USMANOVA Zaira Romanovna, Cand.Sci. (Pol.Sci.), Associate Professor of the Department of Political Science, Faculty of Social Sciences and Mass Communications, Financial University under the Government of the Russian Federation (49 Leningradsky Ave, GSP-3, Moscow, Russia, 125993; ZRUsmanova@fa.ru)

SHASHENKOV Aleksandr Olegovich, postgraduate student of the Department of Political Science, Faculty of Social Sciences and Mass Communications, Financial University under the Government of the Russian Federation (49 Leningradsky Ave, GSP-3, Moscow, Russia, 125993; AOShashenkov2019@edu.fa.ru)

VOROPANOV Sergei Aleksandrovich, postgraduate student of the Department of Political Science, Faculty of Social Sciences and Mass Communications, Financial University under the Government of the Russian Federation (49 Leningradsky Ave, GSP-3, Moscow, Russia, 125993; SAVoropanov2019@edu.fa.ru)

\title{
RISKS OF REFORMING STATE SOCIAL AND ECONOMIC POLICIES IN MODERN RUSSIA
}

\begin{abstract}
The article presents the results of a study conducted in the framework of the project "Socio-economic Inequality in Russia: Trends and Adaptation of Successful Foreign Practices to Overcome Poverty» by a group of young scientists. Part of the research is devoted to the problems of reforming the state social and economic policy in Russia, as well as the possibilities of overcoming negative practices. Groups of risk factors proposed in the article are identified and put into a comparative matrix, which allows qualitatively assessing the interconnection and interdependence of social, economic, political, legal, demographic, environmental, information transformations. The scheme compiled by the authors is characterized by analytical synergism and emergence. In conclusion, the authors found out that most risks are in a state of mutual influence and interdependence. In this regard, it is necessary to harmonize and merge socio-economic measures with virtually all areas of government activity.
\end{abstract}

Keywords: poverty, social exclusion, social policy, economic policy, political reforms, risks

ЕЖОВ Дмитрий Александрович - кандидат политических наук, доцент; доцент департамента политологии факультета социальных наук и массовых коммуникаций Финансового университета при Правительстве РФ (125993, Россия, г. Москва, ГСП-3, Ленинградский пр-кт, 49; president@ lenta.ru)

\section{К ОЦЕНКЕ РИСКОВ РЕАЛИЗАЦИИ НАЦИОНАЛЬНЫХ ПРОЕКТОВ В УСЛОВИЯХ ПАНДЕМИИ COVID-19}

Аннотация. В статье дается оценка рисков реализации национальных проектов 2019-2024 гг. в условиях борьбы с последствиями пандемии коронавирусной инфекции COVID-19. Автор выделяет три типа рисков: экономические, социально-политические и информационные и делает вывод о необходимости модернизации страны, путем достижения которой является реализация национальных проектов.

Ключевые слова: национальные проекты, пандемия коронавируса, стратегия развития России, национальные цели, стратегические задачи, модернизация

$\mathrm{H}$ овые национальные проекты утверждены указом Президента РФ «О национальных целях и стратегических задачах развития Российской Федерации на период до 2024 года» от 7 мая 2018 г. и являются содержательным наполне- 